\title{
Prevalence of tuberculosis among mentally ill patients in conflict-stricken Afghanistan: A cross-sectional study
}

\author{
G. Qader ${ }^{\mathrm{a}, *}$, M.K. Seddiq ${ }^{\mathrm{b}}$, K.M. Rashidi ${ }^{\mathrm{a}}$, A. Hamim ${ }^{\mathrm{a}}$, M.H. Akhgar ${ }^{\mathrm{b}}$, B. Ahmad ${ }^{\mathrm{b}}$, S. Dryer ${ }^{\mathrm{c}}$, \\ A. Somji ${ }^{\mathrm{C}}$, M. Melese ${ }^{\mathrm{c}}$, P.G. Suarez ${ }^{\mathrm{c}}$ \\ ${ }^{a}$ Challenge TB Project, Management Sciences for Health, Kabul, Afghanistan \\ ${ }^{\mathrm{b}}$ National Tuberculosis Program, Ministry of Public Health, Kabul, Afghanistan \\ ${ }^{\mathrm{c}}$ Management Sciences for Health, Arlington, VA, USA
}

\section{A R T I C L E I N F O}

\section{Article history:}

Received 3 June 2019

Received in revised form 16 August 2019

Accepted 19 August 2019

Corresponding Editor: Eskild Petersen, Aarhus, Denmark

\section{Keywords:}

Afghanistan

TB services

Mental disorders

Disease susceptibility

Delivery of health care

Women

\begin{abstract}
A B S T R A C T
Objectives: Tuberculosis (TB) and mental illness share underlying factors such as poverty, malnutrition, and stress. This study's objective was to determine the prevalence of TB among mentally ill patients in Afghanistan.

Methods: A cross-sectional study was conducted in five public and one private health facility. All patients in those centers were screened for TB, and the diagnosis of TB was made with GeneXpert or made clinically by a physician.

Results: Out of 8598 patients registered, 8324 (96.8\%) were reached and $8073(93.9 \%)$ were screened for TB, of whom 1703 (21.1\%) were found to be presumptive TB patients. A total of 275 (16.7\%) were diagnosed with all forms of $\mathrm{TB}$, of whom $90.5 \%$ were women. Eighty-eight (32\%) of them were bacteriologically confirmed and 187 (68\%) were clinically diagnosed. The number needed to screen (NNS) was 29.3 and the number needed to test (NNT) was 6.1. The overall prevalence of TB among mentally ill patients was 3,567/100,000-20 times higher than the national incidence rate. TB was independently associated with married and widowed adults, young adults, females, and oral sleep drug users.

Conclusions: TB among mentally ill patients is very high, and we recommend that TB care and prevention services be integrated into mental health centers.

(c) 2019 The Authors. Published by Elsevier Ltd on behalf of International Society for Infectious Diseases. This is an open access article under the CC BY-NC-ND license (http://creativecommons.org/licenses/bync-nd/4.0/).
\end{abstract}

\section{Introduction}

Mental illness contributes approximately $10 \%$ of the global disease burden, according to Marquez and Saxena (2016). The prevalence of mental disorders and substance abuse in the WHO Eastern Mediterranean Region is estimated to be $11 \%$, and more than $50 \%$ of the world's refugees exist in this region and are also highly vulnerable to mental illness (Shakoor and Hasan, 2016). In a population-based study led by the Centers for Disease Control and Prevention in Afghanistan, the prevalence of depression was found to be $73 \%$ and $59 \%$; of anxiety, $84 \%$ and $59 \%$; and of posttraumatic stress disorder, $48 \%$ and $32 \%$, for females and males, respectively (Cardozo et al., 2005). In a separate study done among Afghanistan refugees living in Iran, anxiety and depression rates were lower than in the previous study, at $39.3 \%$ and $22.1 \%$,

\footnotetext{
* Corresponding author at: Challenge TB Project, 241, Street 4, Karteh She, District 6, Kabul, Afghanistan.

E-mail address: gqader@msh.org (G. Qader).
}

respectively (Hosseini Divkolaye and Burkle, 2017). Afghanistan is also a high-TB-burden country, with an incidence of 189/100,000 population (WHO, 2018). In 2017 Afghanistan notified 47,406 TB cases (WHO, 2018).

Research has shown that people with mental disorders are also susceptible to TB (Singh et al., 2015). In Korea the risk of TB among patients with depression was more than twice as high as it was among individuals with no mental health problems, and TB incidence was higher for patients with severe depression (Hosseini Divkolaye and Burkle, 2017). In Taiwan, prevalence of TB was 1.6 times higher in patients with mental health disorders, and another study found that the incidence of risk of TB in schizophrenic patients was 1.52 times higher than in those without mental illness (Kuo et al., 2013).

The reverse is also true, according to studies that have shown that TB patients have a high risk of developing mental illnesses. In an Ethiopian study, 57\% of TB patients had probable depression (Ambaw et al., 2017), and another study in Ethiopia reported depression in $43.4 \%$ of TB patients and anxiety in $41.5 \%$ (Duko et al., 2015). Duko et al. (2015) also found that among TB/HIV patients, 
the odds of having common mental disorders were 1.7 times higher than among non-TB/HIV patients. In Zambia the rate of any anxiety disorder among TB and TB/HIV patients was $30.8 \%$; major depressive disorder, $11.3 \%$; suicidality, $34.8 \%$; and panic disorder, 4.1\% (van den Heuvel et al., 2013). Post-traumatic disorder among TB patients was $29.6 \%$ in South Africa (Peltzer et al., 2013). Mental illnesses are also a cause of poor quality of life, TB treatment interruption, and poor treatment outcomes (Ambaw et al., 2018; Pachi et al., 2013; Sikjær et al., 2018; Theron et al., 2015).

In Afghanistan rates of mental illness are high because of decades of conflict, stress, and poverty, post-traumatic stress disorders, and illicit drug abuse (Cardozo et al., 2005; Trani et al., 2016; Cardozo et al., 2004; Miller et al., 2008). Considering the high prevalence of mental disorders and TB in Afghanistan, we designed this study to identify the prevalence of TB among mentally ill patients. We believe that the prevalence of TB among mentally ill patients observed in this study will reorient TB and mental health policy and strategies in Afghanistan.

\section{Methodology}

\section{Study setting}

Afghanistan, with a population of 35 million, is one of the highTB-burden countries, with a TB incidence of $189 / 100,000$, based on which we can extrapolate that 65,000 TB patients existed in 2016 (WHO, 2017). The country has been engulfed in conflicts for more than four decades, which has seriously affected the health care system and the health of the citizens (Cardozo et al., 2004). We conducted this study in Kabul, Jalalabad, Kandahar, Herat, and Mazar-e-Sharif provinces, where most of the mental health facilities are located.

\section{Study participants and procedures}

This cross-sectional study was conducted between May and December 2017 in the five public and one private mental health centers in the five provinces. The study included all patients diagnosed with mental health conditions and treated as either outpatients or inpatients and who are receiving follow-up care in the health facilities.

We recruited and trained nurses working in these mental health centers as data collectors. The trained nurses invited all mental health patients registered in the health facilities for TB screening during a regular follow-up visit, via a telephone interview, or through a home visit. Patients who gave verbal consent to participate in the study were invited to come to health facilities, asked for sociodemographic data, and screened for TB using the WHO screening criteria of two or more weeks of cough and two or more of constitutional symptoms such as night sweating and weight loss (WHO, 2012). Patients with those symptoms were considered presumptive TB cases, and further diagnostic investigation was pursued. Presumptive TB cases gave sputum for GeneXpert $\left(\right.$ Xpert $^{\mathbb{R}}$ MTB/RIF assay, Cepheid, Sunnyvale, USA) if they could produce sputum. Two hospitals had a GeneXpert machine, and four hospitals transported the sputum to another hospital for testing. The laboratory professionals who did the GeneXpert tests were trained following the national guidelines, and they received regular on-site mentoring by national laboratory experts. Patients with presumptive TB were instructed to rinse their mouths before collecting the sample to remove any food particles and to cough deeply and forcefully to obtain sputum from the alveoli and bronchial areas. Then the laboratory professional checked the quality of sputum and the quantity of sputum, which should be $2-4 \mathrm{ml}$, although a smaller quantity may be acceptable if

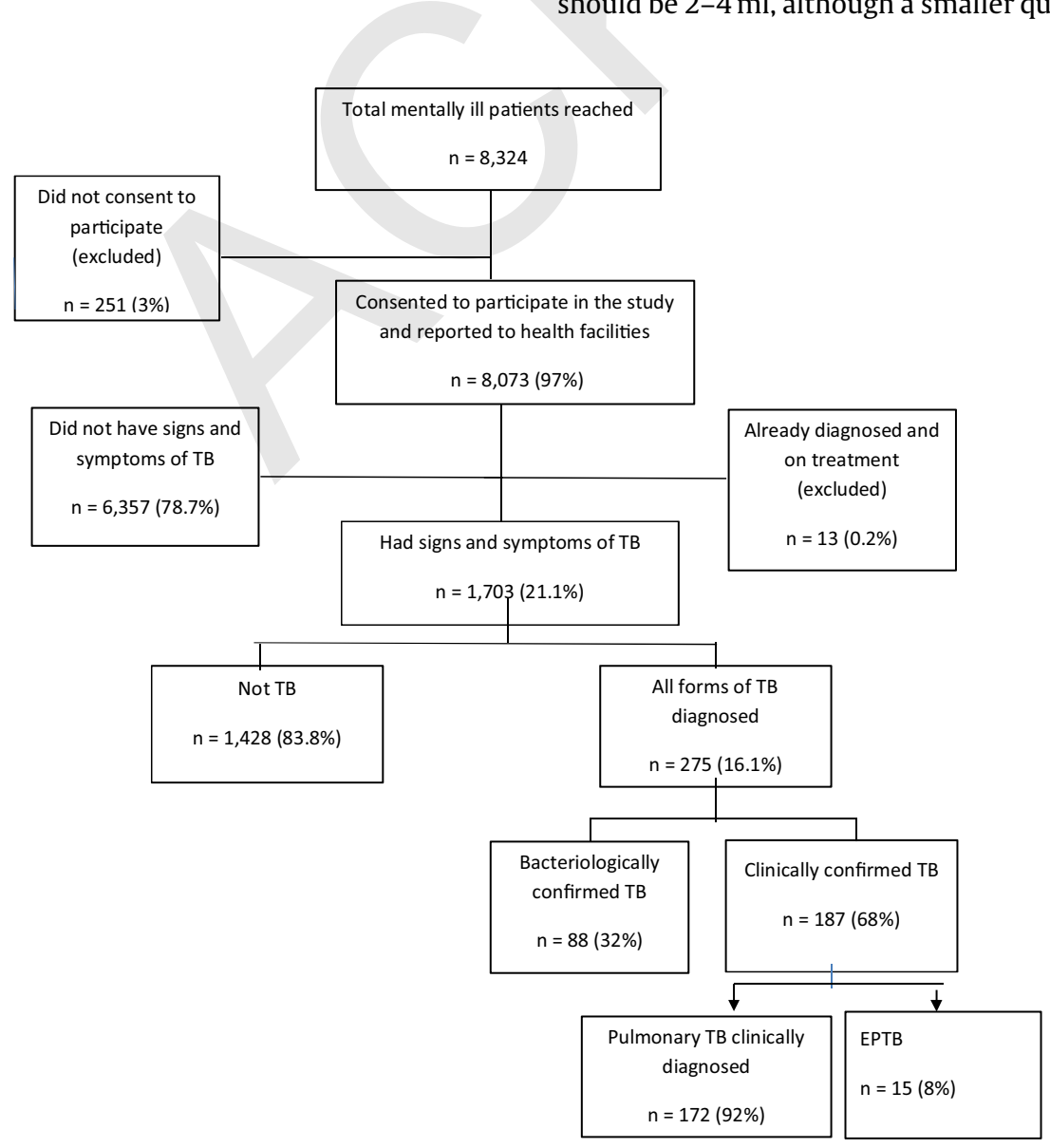

Figure 1. Procedures followed for TB screening of patients with mental health conditions. 
it is mucoid with a minimum of $1 \mathrm{ml}$ (Afghanistan GeneXpert training manual-draft).

Those with other symptoms or who were found to be negative after GeneXpert testing were referred to a hospital physician trained on TB for further examination and diagnosis. The physician ordered chest X-rays for those with presumptive pulmonary TB with nonproductive cough; if there was a lung lesion, the physician might decide to diagnose TB or proceed with other investigations. Chest X-rays were read by two independent radiologists, and if there was a difference in interpretation, a third senior radiologist was used as a tie-breaker. Extra pulmonary TB cases were diagnosed clinically and in a few cases with the support of histology or cytology. Patients who were bacteriologically confirmed to have TB, clinically diagnosed with the support of chest X-ray, or empirically diagnosed were considered TB patients. All mentally ill patients diagnosed with TB then enrolled in treatment in a nearby DOTS center.

\section{Data collection and analysis}

The nurses who had been trained as data collectors collected information on mental illness diagnosis and its category from the cards and registers of the mental health patients. The data collectors also collected data on sociodemographic variables by interviewing the study participants. Then the data collectors interviewed the study participants about signs and symptom of TB and recorded the investigation results in the TB register. The data were entered into SPSS version 23, and the principal investigator checked their consistency. The yield of TB was then calculated using the number needed to screen (NNS) and number needed to test (NNT). NNS is the number of people who have to be screened to detect a single case of active TB; NNT is the number of people with presumptive TB who have to be evaluated to detect a single case of active TB. To address the missed variables, we calculated multiple imputations using $\mathrm{R}$, mean inter-item-correlation, for type of mental disorder and TB. The logistic regression was calculated using the variation inflation factors function of the $R$ Companion to Applied Regression (Fox and Weisberg, 2018). We calculated the association between TB and mental illness, and $\mathrm{p}=<0.05$ was considered to be statistically significant. In this article, mental health condition, mental illness, and mental health disorder are used interchangeably to indicate psychiatric illnesses.

\section{Ethical considerations}

We received written informed consent for each study participant. Their information was kept confidential and not shared with anyone outside of the study team. Those patients who did not consent were excluded from the study. For patients with mental illness who were unable to give consent per the interviewer's assessment or who were under the age of 18 , we sought permission from their next of kin, parent, or guardian, and the screening was done with the assistance of the next of kin.

\section{Results}

In total, 8598 patients with mental illnesses were registered in the six centers that provided mental health services, 8324 (96.8\%) of them were reached; of those, 8073 (93.9\%) gave consent to participate in the study (Figure 1). The majority of the patients with mental health conditions ( 5680 or $70.4 \%$ ) were women, and the mean age of the study participants was 33.6 years, with a median of 30.0 years. The majority of the study participants (5546 or $68.7 \%$ ) were married, while 2109 (26.1\%) were single; 314 (3.9\%) widowed; 12 (0.1\%) divorced; and $22(0.3 \%)$ separated. The most common mental health condition diagnosed was general anxiety disorder, which affected more than half of the patients (4411 or 54.6\%). Depression affected 1141 patients (14.1\%), while 559 (6.9\%) expressed headache alone, 348 (4.3\%) had epilepsy, 321 (4.0\%) suffered from schizophrenia, 218 (2.7\%) experienced panic attacks, $95(1.2 \%)$ had post-traumatic stress disorder, and $32(0.4 \%)$ had psychosis. Four hundred and fourteen study participants (5.1\%) had other types of mental disorders, and for 534 (6.6\%) the diagnosis was not registered or missing. About $21.7 \%$ of the patients with mental illness used one or more substances (Table 1 ).

Out of the 8073 patients with mental illness screened for TB, 1703 (21.1\%) were found to have presumptive TB and 275 (16.1\%) were diagnosed with TB. One hundred and eighty-seven (68\%) of them were clinically diagnosed, and the remaining 88 (32\%) were bacteriologically confirmed (Figure 1 ). Four (4.5\%) of the bacteriologically confirmed TB cases were rifampin-resistant TB.

The NNS to detect a single case of TB was 29.3. The NNTs were 6.1 and 19.3 for all forms of TB and bacteriologically confirmed TB, respectively. Overall the prevalence of $\mathrm{TB}$ among patients with mental health conditions was $3411 / 100,000$ population. If we add the 13 TB patients who were on treatment at the start of the study, the prevalence would be $3567 / 100,000$ population. The prevalence for bacteriologically confirmed cases was 1091/ 100,000 population.

Among the 275 mentally ill patients diagnosed with TB, their mental illness diagnoses were general anxiety (115 or $41.8 \%$ ) and

Table 1

Sociodemographic characteristics of psychiatric patients screened for TB.

\begin{tabular}{|c|c|c|}
\hline Characteristics & & Number (\%) \\
\hline Age & $\begin{array}{l}<15 \\
16-24 \\
25-34 \\
35-44 \\
45+ \\
\text { Missing data }\end{array}$ & $\begin{array}{l}467(5.8 \%) \\
1977(24.5 \%) \\
2057(25.5 \%) \\
1592(19.7 \%) \\
1918(23.8 \%) \\
62(0.8 \%)\end{array}$ \\
\hline Sex & $\begin{array}{l}\text { Male } \\
\text { Female } \\
\text { Missing data }\end{array}$ & $\begin{array}{l}2,392(29.6 \%) \\
5680(70.4 \%) \\
1(0.01 \%)\end{array}$ \\
\hline Marital status & $\begin{array}{l}\text { Married } \\
\text { Divorced } \\
\text { Separated } \\
\text { Widowed } \\
\text { Single } \\
\text { Missing data }\end{array}$ & $\begin{array}{l}5546(68.7 \%) \\
12(0.1 \%) \\
22(0.3 \%) \\
314(3.9 \%) \\
2109(26.1 \%) \\
70(0.9 \%)\end{array}$ \\
\hline Drug use & $\begin{array}{l}\text { Opiates } \\
\text { Oral tablets for sleep/sedation } \\
\text { Mouth snuff } \\
\text { I do not take any drug } \\
\text { Others } \\
\text { Missing data }\end{array}$ & $\begin{array}{l}1,060(13.1 \%) \\
209(2.6 \%) \\
484(6.0 \%) \\
5982(74.1 \%) \\
30(0.4 \%) \\
308(3.8 \%)\end{array}$ \\
\hline Smoking status & $\begin{array}{l}\text { Yes } \\
\text { No } \\
\text { Not disclosed }\end{array}$ & $\begin{array}{l}446(5.5 \%) \\
6,158(76.3 \%) \\
1,469(18.2 \%)\end{array}$ \\
\hline Type of mental illness & $\begin{array}{l}\text { General anxiety } \\
\text { Depression } \\
\text { Headache } \\
\text { Epilepsy } \\
\text { Schizophrenia } \\
\text { Panic attack } \\
\text { Post-traumatic stress disorder } \\
\text { More than one diagnosis } \\
\text { Psychosis } \\
\text { Missing data }\end{array}$ & $\begin{array}{l}1141(14.1 \%) \\
4411(54.6 \%) \\
559(6.9 \%) \\
348(4.3 \%) \\
321(4.0 \%) \\
218(2.7 \%) \\
95(1.2 \%) \\
414(5.1 \%) \\
32(0.4 \%) \\
534(6.6 \%)\end{array}$ \\
\hline HIV status (patient report) & $\begin{array}{l}\text { Positive } \\
\text { Negative } \\
\text { Unknown/not disclosed }\end{array}$ & $\begin{array}{l}8(0.1 \%) \\
6212(76.9 \%) \\
1,853(23.0 \%)\end{array}$ \\
\hline
\end{tabular}


depression (72 or $26.2 \%$ ), respectively. In the multivariate analysis, people aged between $16-24,25-34$, and > 45 years (AOR 2.96: $95 \%$ CI 1.62-10.01, AOR 1.89: 95\% CI 1.08-10.06, and AOR 2.81: 95\% CI 1.03-9.9) respectively; married and widowed patients (AOR 1.57: 95\% CI 1.02-2.48 and 2.05: 1.03-4:00) respectively; females (AOR 3.1: 95\% CI 2.05-4.86); and users of oral tablets for sleep/sedation (AOR 3.1: 95\% CI 3-4.72) were all independently associated with TB. Depressed patients (AOR 0.26: $95 \%$ CI $0.17-0.40$ ) had a $74 \%$ lower chance of TB (Table 2).

\section{Discussion}

The prevalence of mental disorders in Afghanistan is as high as $50 \%$ (Alemi et al., 2014). Our study found that the prevalence of TB among patients with common mental health disorders was 3,567/ 100,000 population, which is almost 20 times higher than the incidence rate in the general population (WHO, 2018). As described in the literature, various factors could explain the high TB prevalence among mentally ill people. The complex interplay among poverty, undernutrition, immunosuppression, behavioral factors, and substance abuse might have contributed to the TB epidemic in Afghanistan (Theron et al., 2015). Poverty is a common driver of TB (WHO, 2013; Figueroa-Munoz and Ramon-Pardo, 2008; Lund et al., 2011) and mental illnesses (Lund et al., 2011). Mental illness can result from having TB disease because of stigma, social vulnerabilities such as malnutrition, and the side effects of TB drugs (Sweetland et al., 2017). The poor lack adequate housing and food; experience more stress than people who are better off; and lack access to health care. The situation of people with mental illness is worse because of neglect, poverty, or lack of understanding about the need for care (Peltzer et al., 2013; Figueroa-Munoz and Ramon-Pardo, 2008). The relationship of malnutrition to mental illness has been established, because malnutrition lowers immunity and people with mental illness, especially those who are depressed, can be vulnerable to malnutrition (WHO, 2013; Gupta et al., 2009).

In the case of Afghanistan, because of decades of war, mental illness is very common. In one study that compared the rates of mental illness among disabled and non-disabled people aged 15 years and above in Afghanistan, the rates of depression were 67.7\% and $71.7 \%$, and the rates of anxiety were $72.2 \%$ and $84.6 \%$ for nondisabled and disabled people, respectively. In the same study, the rate of post-traumatic stress disorder for both groups was $42.1 \%$, and with respect to both depression and post-traumatic stress disorder, women had poorer mental health than men (Cardozo et al., 2004). Another study also reported higher rates of mental illness in Afghan women as compared to men (Cardozo et al., 2002). In our study, more women (249 or $90.5 \%$ ) were diagnosed with TB than men $(\mathrm{p}<0.001)$, and $70.4 \%$ of the study subjects were women. In developing countries, a high risk of mental illness in women has been reported, mainly due to high poverty among women (Lund et al., 2011; Patel et al., 1999). These factors could explain the high number of TB cases we found among mentally ill patients in our study.

Conflict, mental illness, and poverty, all of which feed the TB epidemic, are also associated (Singh et al., 2015; Pachi et al. 2013; Theron et al., 2015). After decades of civil war and several natural disasters, close to 5 million Afghan citizens have migrated to other countries for security and better living conditions. Within Afghanistan, 5.8 million Afghans have returned since 2002; there is also an unknown number of internal migrants; the exact locations of returned refugees and migrants are not known

Table 2

Associations among TB, type of mental illness, and duration of mental illness.

\begin{tabular}{|c|c|c|c|c|}
\hline Variables & & TB Cases (\%) & Unadjusted Odds Ratio (95\% CI) & Adjusted Odds Ratio (95\% CI) \\
\hline \multirow{9}{*}{ Type of mental disorder } & Headache & $33 / 559(5.9)$ & 1 & \\
\hline & Depression & $72 / 4411$ (1.6) & $0.24(0.16-0.37)$ & $0.26(0.17-0.40)$ \\
\hline & General anxiety & $115 / 1141(10.7)$ & $1.66(1.14-2.48)$ & $1.39(0.94-2.09)$ \\
\hline & Panic attack & $4 / 218(1.8)$ & $0.28(0.08-0.7)$ & $0.42(0.12-1.08)$ \\
\hline & Post-traumatic stress disorder & $3 / 95(3.1)$ & $0.65(0.19-1.66)$ & \\
\hline & Schizophrenia & $5 / 321(1.5)$ & $0.22(0.08-0.52)$ & $0.42(0.12-1.08)$ \\
\hline & Other (more than one diagnosis) & $27 / 414(6.5)$ & $1(0.59-1.67)$ & \\
\hline & Epilepsy & $6 / 348(1.7)$ & $0.26(0.1-0.57)$ & $0.46(0.17-1.06)$ \\
\hline & Psychosis & $1 / 32(3.1)$ & $0.47(0.03-2.28)$ & \\
\hline \multirow[t]{4}{*}{ Duration of mental illness (years) } & $<1$ & $79 /, 1846(4.2)$ & 1 & \\
\hline & $1-5$ & $125 / 4,164(45.5)$ & $0.66(0.51-0.87)$ & $0.92(0.69-1.22)$ \\
\hline & $6-9$ & $18 / 663(2.7)$ & $0.60(0.36-0.96)$ & $0.87(0.51-1.43)$ \\
\hline & $\geq 10$ & $20 / 302(6.6)$ & $0.59(0.35-0.93)$ & $0.89(0.52-1.45)$ \\
\hline \multirow[t]{5}{*}{ Marital status } & Single & $37 / 2109(0.1)$ & 1 & \\
\hline & Married & $251 / 5,582(4.4)$ & $2.28(1.62-3.29)$ & $1.57(1.02-2.48)$ \\
\hline & Divorced & $0 / 12(0)$ & & \\
\hline & Separated & $2 / 22(9.0)$ & $5.39(0.84-19.32)$ & \\
\hline & Widowed & $20 / 314(6.3)$ & $3.79(2.13-6.54)$ & $2.05(1.03-4.00)$ \\
\hline \multirow[t]{5}{*}{ Age } & $<15$ & $4 / 467(0.8)$ & 1 & \\
\hline & $16-24$ & $65 / 1977(3.3)$ & $3.93(1.62-12.99)$ & $2.96(1.16-10.01)$ \\
\hline & $25-34$ & $75 / 2057(3.6)$ & $4.51(1.86-14.83)$ & $2.89(1.08-10.06)$ \\
\hline & $35-44$ & $55 / 1592(3.4)$ & $4.14(1.69-13.73)$ & $2.38(0.87-8.4)$ \\
\hline & $45+$ & $74 / 1918(3.8)$ & $4.65(1.92-15.32)$ & $2.81(1.03-9.9)$ \\
\hline \multirow[t]{2}{*}{ Sex } & Male & $26 / 2,392$ & 1 & \\
\hline & Female & $249 / 5680(4.3)$ & $4.17(2.83-6.41)$ & $3.10(2.05-4.86)$ \\
\hline \multirow[t]{5}{*}{ Drug use } & I do not take any drug & $224 / 5982(3.7)$ & 1 & \\
\hline & Opiates & $0 / 1,060$ & & \\
\hline & Oral tablets for sleep/sedation & $31 / 209$ (33.9) & $4.41(2.9-6.51)$ & $3.13(2.02-4.72)$ \\
\hline & Mouth snuff & $16 / 468(3.2)$ & $0.87(0.5-1.41)$ & \\
\hline & Others & $2 / 30(6.7)$ & $1.76(0.28-5.89)$ & \\
\hline
\end{tabular}


(UNHCR update 2015-2016). Refugees and migrants are at higher risk of developing TB and MDR-TB than the rest of the native population (Lönnroth et al., 2017). In a meta-analysis study among Afghan refugees, there was moderate to high depression and posttraumatic stress disorder, factors associated with distress, conflict, and loss of family and friends (Alemi et al., 2014). The interplays among migration, poverty, mental illness, and TB should be considered in Afghanistan because these risk factors are common in this setting.

The NNS of 29.3 is lower than what is reported for contact screenings in Uganda, 131 (Sekandi et al., 2014), and 40 in Ethiopia (Jerene et al., 2015) but higher than the reported NNS of 19 in India (Nair et al., 2016). In another contact investigation study in Afghanistan, we found out that the NNS to diagnose a single case of all forms of TB was 59.2 and the NNT was 11.1 (unpublished data of the authors). The contacts of people with TB have a higher risk of developing TB disease than persons having no contacts, and these countries (Uganda and Ethiopia) have a high HIV prevalence, while HIV prevalence in Afghanistan is very low, but the low NNS in our study shows that the risk of TB among the mentally ill is even higher than the risk reported for contacts in Uganda, Ethiopia, and Afghanistan. The NNT was also high, 6.1, which is close to the NNT reported in Ghana, 8 for contact screening (Ohene et al., 2018). The NNS and NNT also depend on the TB incidence of the country, and Afghanistan has a high TB incidence, at 189/100,000 population (WHO, 2018).

We found out that among mentally ill patients who were married women or widowed, their marital status was independently associated with TB. In a study in Ethiopia, 54\% of TB patients were reported to have depression, and it was higher for women, married people, and divorced people (Ambaw et al., 2017); a study in South Korea reported that males with depression had a higher risk of TB than women (Oh et al., 2017). South Korea is a low-TBincidence country (WHO, 2018), and the difference in TB incidence vis-a-vis sex versus that in Afghanistan could be explained by the difference in incidence, in which Ethiopia is similar to Afghanistan. Women in Afghanistan have a higher rate of mental illness than men (73\% vs. $59 \%$ for depression, $84 \%$ vs. $59 \%$ for anxiety, $48 \%$ vs. $32 \%$ for post-traumatic disorders) (Cardozo et al., 2005). The high burden of TB among Afghan women, therefore, can be also explained by this difference in the rate of mental illness between the two sexes.

Age was significantly associated with TB for mentally ill patients aged $16-34$ and $>45$. It is reported that the burden of mental illness is more common in early young adults and in the middle age of 25 and 50 years, and drug use is also more common in these age brackets. According to a global study, Afghanistan has one of the highest rates of mental illness among young adults, mainly related to ongoing conflict, and probably illicit drug use (Whiteford et al., 2013). This could be one reason for the high association of TB with mental illness in this age group seen in our study.

Although we did not study the effects of medicines used to treat mental illness or the effects of TB drugs, the literature shows that clozapine was the only antipsychotic agent associated with a 63\% increased risk of TB $(A O R=1.63, p=0.014)$ (Liu et al., 2018). TB drugs such as cycloserine have also been associated with depression (Doherty et al., 2013). Health workers should consider these interactions during the management of mentally ill and TB patients.

\section{Limitations}

One limitation of this study is that we did not substantiate the accuracy of diagnoses of mental illness. We also did not test people for HIV because the national guidelines do not recommend that all TB patients be tested for HIV, since HIV prevalence is very low in
Afghanistan. We do not know if it is also low among mentally ill patients.

\section{Conclusion and recommendations}

The burden of TB is very high among mentally ill people. Because the two diseases are synergistic and Afghanistan has high burdens of both TB and mental illness, integration of TB services into mental health facilities is important. Mental health experts need to be trained on TB screening and diagnosis and the interplay of the two diseases.

\section{Authors' contributions}

Designed the study and led the research: G. Qader, M. Melese, K. M. Rashidi, and P. G. Suarez. All others participated in the data analysis and writing. All authors have approved the manuscript for submission.

\section{Acknowledgements}

We thank the Afghanistan Ministry of Public Health and National TB Program and all the health workers, laboratory professionals, and TB program coordinators who participated in this study. Barbara K. Timmons edited the manuscript.

\section{Funding}

The United States Agency for International Development (USAID) funded this study through the Challenge TB project under cooperative agreement number AID-OAA-A-14-00029. The contents of the article are the responsibility of the authors alone and do not necessarily reflect the views of USAID or the US government.

\section{Conflicts of interest}

The authors declare no conflicts of interest.

\section{References}

Alemi Q, James S, Cruz R, Zepeda V, Racadio M. Psychological distress in Afghan refugees: a mixed-method systematic review. J Immigr Minor Health 2014;16:1247-61, doi:http://dx.doi.org/10.1007/s10903-013-9861-1.

Ambaw F, Mayston R, Hanlon C, Alem A. Burden and presentation of depression among newly diagnosed individuals with TB in primary care settings in Ethiopia. BMC Psychiatry 2017;17:57, doi:http://dx.doi.org/10.1186/s12888017-1231-4.

Ambaw F, Mayston R, Hanlon C, Medhin G, Alem A. Untreated depression and tuberculosis treatment outcomes, quality of life and disability, Ethiopia. Bull World Health Organ 2018;96:243-55, doi:http://dx.doi.org/10.2471/BLT.17.192658.

Cardozo BL, Bilukha OO, Crawford CAG, Shaikh I, Wolfe MI, Gerber ML, et al. Mental health, social functioning, and disability in postwar Afghanistan. JAMA 2004;292:575-84. . (Accessed 9 May 2019) https://jamanetwork.com/journals/jama/fullarticle/199195.

Cardozo BL, Bilukha OO, Gotway CA, Wolfe MI, Gerber ML, Anderson M. Report from the CDC: mental health of women in postwar Afghanistan. J Womens Health (Larchmt) 2005; 14:285-93.

Doherty AM, Kelly J, McDonald C, O'Dywer AM, Keane J, Cooney J. A review of the interplay between tuberculosis and mental health. Gen Hosp Psychiatry 2013;35:398-406, doi:http://dx.doi.org/10.1016/j.genhosppsych.2013.03.018.

Duko B, Gebeyehu A, Ayano G. Prevalence and correlates of depression and anxiety among patients with tuberculosis at WolaitaSodo University Hospital and Sodo Health Center, WolaitaSodo, South Ethiopia, cross sectional study. BMC Psychiatry 2015;15:2014, doi:http://dx.doi.org/10.1186/s12888-015-0598-3.

Figueroa-Munoz JI, Ramon-Pardo P. Tuberculosis control in vulnerable groups. Bull World Health Organ 2008;86:733-5.

Fox J, Weisberg S. An R companion to applied regression. 3rd ed. Thousand Oaks, CA: Sage; 2018.

Gupta KB, Gupta R, Atreja A, Verma M, Vishvkarma S. Tuberculosis and nutrition. Lung India 2009;26:9-16, doi:http://dx.doi.org/10.4103/0970-2113.45198.

Hosseini Divkolaye NS, Burkle [175_TD\$DIFF]Jr. FM. The enduring health challenges of Afghan immigrants and refugees in Iran: a systematic review. PLoS Curr. 2017;9:, doi: http://dx.doi.org/10.1371/currents.dis.449b4c549951e359363a90a7f4cf8fc4. 
Jerene D, Melese M, Kassie Y, Alem G, Daba SH, Hiruye N, et al. The yield of a tuberculosis household contact investigation in two regions of Ethiopia. Int J Tuberc Lung Dis 2015;19:898-903, doi:http://dx.doi.org/10.5588/ijtld.14.0978.

Kuo S-C, Chen Y-T, Li S-Y, Lee Y-T, Yang AC, Chen T-L, et al. Incidence and outcome of newly-diagnosed tuberculosis in schizophrenics: a 12-year, nationwide, retrospective longitudinal study. BMC Infect Dis 2013;13:351, doi:http://dx. doi.org/10.1186/1471-2334-13-351.

Liu H-C, Hung GC-L, Yang S-Y, Liao Y-T, Pan C-H, Chen C-C, et al. Antipsychotic drugs and risk of newly diagnosed tuberculosis in schizophrenia. Psychiatry Clin Neurosci 2018;72:789-800, doi:http://dx.doi.org/10.1111/pcn.12736.

Lönnroth K, Mor Z, Erkens C, Bruchfeld J, Nathavitharana RR, van der Werf MJ, et al. Tuberculosis in migrants in low-incidence countries: epidemiology and intervention entry points. Int J Tuberc Lung Dis 2017;21:624-37, doi:http:// dx.doi.org/10.5588/ijtld.16.0845.

Lund C, De Silva M, Plagerson S, Cooper S, Chisholm D, Das J, et al. Poverty and mental disorders: breaking the cycle in low-income and middle-income countries. Lancet 2011;378:1502-14, doi:http://dx.doi.org/10.1016/S0140-6736 (11)60754-X.

Marquez PV, Saxena S. Making mental health a global priority. Cerebrum 2016; pii: cer-10https://www.ncbi.nlm.nih.gov/pmc/articles/PMC5198754/(Accessed 9 May 2019).

Miller KE, Omidian P, Rasmussen A, Yaqubi A, Daudzai H. Daily stressors, war experiences, and mental health in Afghanistan. Transcult Psychiatry 2008;45:611-38, doi:http://dx.doi.org/10.1177/1363461508100785.

Nair D, Rajshekhar N, Klinton JS, Watson B, Velayutham B, Tripathy JP, et al Household contact screening and yield of tuberculosis cases: a clinic based study in Chennai, South India. PLoS One 2016;11(9)e0162090, doi:http://dx.doi. org/10.1371/journal.pone.0162090.

Oh KH, Choi H, Kim EJ, Kim KJ, Cho SI. Depression and risk of tuberculosis: a nationwide population based cohort study. Int J Tuberc Lung Dis 2017;21 (7):804-9, doi:http://dx.doi.org/10.5588/ijtld.17.0038.

Ohene SA, Bonsu F, Hanson-Nortey NN, Sackey A, Danso S, Afutu F, et al. Yield of tuberculosis among household contacts of tuberculosis patients in Accra, Ghana. Infect Dis Poverty 2018;7(1):14, doi:http://dx.doi.org/10.1186/s40249018-0396-5.

Pachi A, Bratis D, Moussas G, Tselebis A. Psychiatric morbidity and other factors affecting treatment adherence in pulmonary tuberculosis patients. Tuberc Res Treat 2013;2013:489865, doi:http://dx.doi.org/10.1155/2013/489865.

Patel V, Araya R, de Lima M, Ludermir A, Todd C. Women, poverty and common mental disorders in four restructuring societies. Soc Sci Med 1999;49:1461-71, doi:http://dx.doi.org/10.1016/S0277-9536(99)00208-7.

Peltzer K, Naidoo P, Matseke G, Louw J, McHunu G, Tutshana B. Prevalence of posttraumatic stress symptoms and associated factors in tuberculosis (TB), TB retreatment and/or TB-HIV co-infected primary public health-care patients in three districts in South Africa. Psychol Health Med 2013;18:387-97, doi:http:// dx.doi.org/10.1080/13548506.2012.726364.

Shakoor S, Hasan R. Tuberculosis in vulnerable populations in Eastern Mediterranean Region: implications for control. Int J Mycobacteriol 2016;5(Suppl 1):S15, doi:http://dx.doi.org/10.1016/j.ijmyco.2016.08.012.

Sekandi JN, List J, Luzze H, Yin XP, Dobbin K, Corso PS, et al. Yield of undetected tuberculosis and human immune deficiency various co-infection from active case finding in urban Uganda. Int J Tuberc Lung Dis 2014;18:13-9.

Sikjær MG, Løkke A, Hilberg O. The influence of psychiatric disorders on the course of lung cancer, chronic obstructive pulmonary disease and tuberculosis. Respir Med 2018;135:35-41, doi:http://dx.doi.org/10.1016/j.rmed.2017.12.012.

Singh L, Pardal PK, Prakash J. Psychiatric morbidity in patients of pulmonary tuberculosis-an observational study. Ind Psychiatry J 2015;24:168-71, doi: http://dx.doi.org/10.4103/0972-6748.181722.

Sweetland AC, Kritski A, Oquendo MA, Sublette ME, Norcini Pala A, Silva LRB, et al. Addressing the tuberculosis-depression syndemic to end the tuberculosis epidemic. Int J Tuberc Lung Dis 2017;21:852-61, doi:http://dx.doi.org/10.5588/ ijtld.16.0584.

Theron G, Peter J, Zijenah L, Chanda D, Mangu C, Clowes P, et al. Psychological distress and its relationship with non-adherence to TB treatment: a multicentre study. BMC Infect Dis 2015;15:253, doi:http://dx.doi.org/10.1186/s12879-0150964-2.

Trani J-F, Ballard E, Bakhshi P, Hovmand P. Community based system dynamic as an approach for understanding and acting on messy problems: a case study for global mental health intervention in Afghanistan. Confl Health 2016;10:25, doi: http://dx.doi.org/10.1186/s13031-016-0089-2.

UN High Commissioner for Refugees (UNHCR). Solutions strategy for Afghan refugees: regional overview: update 2015-2016. https://reliefweb.int/sites reliefweb.int/files/resources/542522922.pdf. (Accessed 8 May 2019).

van den Heuvel L, Chishinga N, Kinyanda E, Weiss H, Patel V, Ayles H, et al. Frequency and correlates of anxiety and mood disorders among TB- and HIV-infected Zambians. AIDS Care 2013;25:1527-35, doi:http://dx.doi.org/10.1080/ 09540121.2013 .793263

Whiteford HA, Degenhardt L, Rehm J, Baxter AJ, Ferrari AJ, Erskine HE, et al. Global burden of disease attributable to mental and substance use disorders: findings from the Global Burden of Disease Study 2010. Lancet 2013;382(9904):1575-86, doi:http://dx.doi.org/10.1016/S0140-6736(13)61611-6.

World Health Organization (WHO). Recommendations for investigating contacts of persons with infectious tuberculosis in low-and middle-income countries. Geneva: WHO; 2012.

WHO. Guideline: nutritional care and support for patients with tuberculosis. 2013. (Accessed 9 May 2019) http://www.ncbi.nlm.nih.gov/books/NBK189867/.

WHO. Global tuberculosis report 2017. Geneva: WHO; 2017.

WHO. Global tuberculosis report 2018. Geneva: WHO; 2018. 